\title{
The ABO Blood Group is an Independent Prognostic Factor in Patients with Ovarian Cancer
}

\author{
Qian Song1, Jun-zhou $\mathrm{Wu}^{2}$, Sheng Wang1, Zhong-bo Chen ${ }^{3 凶}$ \\ 1. Department of Clinical Laboratory, Institute of cancer research and basic medical sciences of Chinese Academy of Sciences, Cancer hospital of University of \\ Chinese Academy of Sciences, Zhejiang Cancer Hospital, Hangzhou, Zhejiang, People's Republic of China \\ 2. Cancer Research Institute, Institute of cancer research and basic medical sciences of Chinese Academy of Sciences, Cancer hospital of University of Chinese \\ Academy of Sciences, Zhejiang Cancer Hospital \& Key Laboratory Diagnosis and Treatment Technology on Thoracic Oncology of Zhejiang Province, \\ Hangzhou, Zhejiang, People's Republic of China \\ 3. Department of Gynecologic Oncology, Institute of cancer research and basic medical sciences of Chinese Academy of Sciences, Cancer hospital of University \\ of Chinese Academy of Sciences, Zhejiang Cancer Hospital, Hangzhou, Zhejiang, People's Republic of China \\ $\triangle$ Corresponding author: Zhong-bo Chen, Department of Gynecologic Oncology, Institute of cancer research and basic medical sciences of Chinese Academy of \\ Sciences, Cancer hospital of University of Chinese Academy of Sciences, Zhejiang Cancer Hospital, Hangzhou, Zhejiang, 310022, People's Republic of China. Tel: \\ 86-571-88122509; Fax: 86-571-88122509; E-mail: chenzb@zjcc.org.cn.
}

(C) The author(s). This is an open access article distributed under the terms of the Creative Commons Attribution License (https://creativecommons.org/licenses/by/4.0/). See http://ivyspring.com/terms for full terms and conditions.

Received: 2019.05.01; Accepted: 2019.08.26; Published: 2019.10.22

\begin{abstract}
Previous studies have suggested a relationship between $A B O$ blood group and clinical outcome of various cancers. Nevertheless, little is known about the association between ABO blood group and survival in patients with ovarian carcinoma. This study aimed to investigate the prognostic significance of $A B O$ blood group in patients with ovarian carcinoma. 941 patients who were newly diagnosed with ovarian carcinoma between February 2007 and February 2016 were enrolled in the present study. The relationship between $A B O$ blood type and clinical features in patients with ovarian cancer was analyzed using chi-square tests. Overall survival (OS) stratified by B antigen was evaluated using log-rank test and Kaplan-Meier method. Presence of the $B$ antigen (B/AB) had a worse $O S$ than those in the absence of the $B$ antigen $(A / O)$ in all patients with ovarian cancer, especially in patients with FIGO stage I, IV, and menopause. Presence of the $B$ antigen (B/AB) was significantly correlated with $O S$ than those with non-B antigen (A/O) (hazard ratios 1.342; $95 \%$ confidence interval 1.069-1.685; $\mathrm{P}=0.011)$. Multivariate analyses revealed that presence of the $B$ antigen $(B / A B)$ was independently associated with OS (hazard ratios 1.532 ; $95 \%$ confidence interval 1.111-2.112; $P=0.009)$. This study indicated that presence of the $B$ antigen $(B / A B)$ was an unfavorable prognostic factor in ovarian carcinoma, especially in patients with FIGO stage I, IV, and menopause.
\end{abstract}

Key words: ABO blood group, B antigen, ovarian cancer, prognosis

\section{Introduction}

Ovarian cancer is identified as the seventh most commonly diagnosed carcinoma in the world and the fifth leading cause of carcinoma-related death in women [1-2]. Because of the lack of screening for diagnosis of ovarian cancer at early stage, approximately 85 percent of cases of ovarian cancer are diagnosed at an advanced stage (III/IV) [3]. Patients with ovarian cancer face with worse prognosis that the 5-year survival rate is only $30 \%$ [4]. Several factors are correlated with the survival of ovarian cancer, including FIGO stage, residual disease, and grade of differentiation [5-7]. Nevertheless, patients with the similar FIGO stage and grade have different prognosis. Therefore, it is imperative to identify accurate, inexpensive and reproducible prognosis factors of ovarian cancer.

Some studies have suggested the relationship between the $\mathrm{ABO}$ blood type and the risk of various carcinomas, including colorectal cancer, renal cell carcinoma, and pancreatic carcinoma [8-10]. 
Meanwhile, in a recent analysis of 49,153 women in 1 prospective study, individuals with presence of the $B$ antigen $(B / A B)$ had an increased incidence of ovarian cancer compared with those with non-B antigen (A/O) [11]. While several retrospective studies have showed that blood type A was correlated with a higher incidence of ovarian carcinoma compared with blood type O [12-14]. However, few studies have evaluated the association between $\mathrm{ABO}$ blood group and the prognosis among patients with ovarian cancer. Two retrospective researches reported that blood type A was correlated with a worse clinical outcome in 256 patients with ovarian cancer and in 92 patients with ovarian cancer [15-16]. Therefore, we aimed to evaluate the relationship between $\mathrm{ABO}$ blood group and the survival of patients with ovarian carcinoma.

\section{Materials and Methods}

\section{Patient selection}

941 patients who were newly diagnosed with primary ovarian carcinoma from February 2007 to February 2016 at the Zhejiang Cancer Hospital were selected for this retrospective research. The diagnosis of ovarian carcinoma was confirmed by a postoperative pathology diagnosis. The criteria of pathology diagnosis were in accordance with the World Health Organization classification standard. The inclusive criteria as follows: (1) ovarian cancer was pathologically confirmed; (2) complete clinical records, including age, FIGO stage, histologic differentiation, menopause, family history of cancer, ascites at surgery, residual disease, and follow-up data; (3) sufficient clinical examination, including ABO blood group, preoperative serum CA125 level. The $A B O$ blood type $(A / B / A B / O)$ was checked by anti-A and anti-B blood grouping reagents (monoclonal antibody). CA125 antigen was quantified in serum in Zhejiang cancer hospital using chemiluminescence microparticle immune assay (CMIA) [ARCHITECT CA125 II Reagent Kit, Abbott]. In the first half year undergoing surgery, patients were followed up at the first, third and sixth months. Patients were followed up every six months during the following years. The follow up examinations include physical examination, serum CA125 level and blood routine examination el at. This retrospective study was approved by the Ethics Committee of Zhejiang Cancer Hospital. All patients provided written informed consent.

\section{Statistical analysis}

The relationship between $\mathrm{ABO}$ blood type and clinical features in patients with ovarian carcinoma was analyzed using chi-square tests. The relationship between presence of $\mathrm{B}$ antigen $(\mathrm{B} / \mathrm{AB})$ and clinical features in patients with ovarian cancer was also evaluated using chi-square tests. Overall survival (OS) was calculated using the Kaplan-Meier method and the log-rank test. Hazard ratio and 95\% confidence interval were calculated using COX regression analyses. The overall survival curve was evaluated by GraphPad Prism 7 software. All data were examined by the SPSS software (version 19.0). A value of $\mathrm{P}<0.05$ was regarded as statistical significance.

\section{Results}

\section{Patient characteristics}

We enrolled 941 patients with ovarian cancer in the study from February 2007 to February 2016. The median age of all individuals was 54 years (range: 23-81 years). 51 patients had FIGO stage I, 76 patients had FIGO stage II, 651 patients had FIGO stage III, and 163 patients had FIGO stage IV. A total of 795 patients had serous cancer, and 146 patients had other. 322 patients had blood type A (34.2\%), 250 patients had blood type B $(26.6 \%), 75$ patients had blood type $\mathrm{AB}(8.0 \%)$, and 294 patients had blood type $\mathrm{O}(31.2 \%)$. No significant association was determined between the $\mathrm{ABO}$ blood group and age, menopause, FIGO stage, family history of cancer, ascites at surgery, residual disease, histology, grade, lymph node stats, Rh factor, and CA125 at diagnosis (Table $1)$.

\section{Correlation between presence of the $B$ antigen (B/AB) and clinical features}

The correlation between presence of the $B$ antigen $(\mathrm{B} / \mathrm{AB})$ and clinical characteristics was listed in Table 2. 325 patients had presence of the $B$ antigen $(\mathrm{B} / \mathrm{AB})(34.5 \%)$, and 616 patients had presence of the non-B antigen (A/O) $(65.5 \%)$. None of the clinical features was significantly correlated with presence of the $B$ antigen $(B / A B)$, including age, menopause, FIGO stage, family history of cancer, ascites at surgery, residual disease, histology, lymph node stats, $\mathrm{Rh}$ factor, and CA125 at diagnosis. Nevertheless, presence of the $\mathrm{B}$ antigen $(\mathrm{B} / \mathrm{AB})$ was notably associated with grade $(\mathrm{P}=0.027)$.

\section{Prognostic variables for OS}

The Kaplan-Meier curves suggested that patients in blood type B had a worse survival compared with those in the non-B blood types $(\mathrm{P}=0.048)$ (Figure 1). Furthermore, we evaluated the prognostic value of the $A B O$ blood group with presence of the $B$ antigen $(B / A B)$ and non- $B$ antigen $(A / O)$, patients with presence of the $B$ antigen $(B / A B)$ had a worse survival compared to the patients with 
presence of the non- $\mathrm{B}$ antigen $(\mathrm{A} / \mathrm{O})(\mathrm{P}=0.010)$ (Figure 2).

Univariate analysis indicated that in addition to presence of the $\mathrm{B}$ antigen $(\mathrm{B} / \mathrm{AB}) \quad(\mathrm{P}=0.011)$, menopause $(\mathrm{P}=0.028)$, FIGO stage I $(\mathrm{P}=0.008)$, FIGO stage II $(\mathrm{P}=0.005)$, ascites at surgery $(\mathrm{P}=0.006)$, residual disease $(\mathrm{P}=0.008)$, and lymph node stats $(\mathrm{P}=0.022)$ were also significantly correlated with $\mathrm{OS}$. In the multivariate analysis, menopause $(\mathrm{P}=0.010)$, FIGO stage I $(\mathrm{P}=0.008)$, FIGO stage II $(\mathrm{P}=0.027)$, presence of the $\mathrm{B}$ antigen $(\mathrm{B} / \mathrm{AB})(\mathrm{P}=0.009)$ were significantly associated with OS (Table 3 ).

Table 1. Relationship between $A B O$ blood group and clinicopathological features in patients with ovarian cancer

\begin{tabular}{|c|c|c|c|c|c|c|}
\hline Characteristics & $\begin{array}{l}\text { Total } \\
(\mathrm{N}=941)\end{array}$ & $\begin{array}{l}\mathrm{A} \\
(\mathrm{N}=322)\end{array}$ & $\begin{array}{l}B \\
(N=250)\end{array}$ & $\begin{array}{l}\mathrm{AB} \\
(\mathrm{N}=75)\end{array}$ & $\begin{array}{l}\mathrm{O} \\
(\mathrm{N}=294)\end{array}$ & $\begin{array}{l}P \\
\text { value }\end{array}$ \\
\hline $\begin{array}{l}\text { Age[median } \\
\text { (range),years] }\end{array}$ & $54(23-81)$ & $55(23-80)$ & $54(25-80)$ & $\begin{array}{l}55 \\
(36-77)\end{array}$ & $\begin{array}{l}53 \\
(26-81)\end{array}$ & \\
\hline$\leq 55$ & 503 & 170 & 134 & 38 & 161 & 0.920 \\
\hline$>55$ & 438 & 152 & 116 & 37 & 133 & \\
\hline \multicolumn{7}{|l|}{ Menopause } \\
\hline Yes & 542 & 191 & 142 & 47 & 162 & 0.574 \\
\hline No & 399 & 191 & 108 & 28 & 132 & \\
\hline \multicolumn{7}{|l|}{ FIGO stage } \\
\hline I & 51 & 16 & 17 & 5 & 13 & 0.504 \\
\hline II & 76 & 25 & 18 & 7 & 26 & \\
\hline III & 651 & 218 & 184 & 50 & 199 & \\
\hline IV & 163 & 63 & 31 & 13 & 56 & \\
\hline \multicolumn{7}{|c|}{$\begin{array}{l}\text { Family history } \\
\text { of cancer }\end{array}$} \\
\hline Yes & 307 & 104 & 76 & 29 & 98 & 0.595 \\
\hline No & 634 & 218 & 174 & 46 & 196 & \\
\hline \multicolumn{7}{|l|}{$\begin{array}{l}\text { Ascites at } \\
\text { surgery }\end{array}$} \\
\hline Yes & 448 & 164 & 108 & 31 & 145 & 0.523 \\
\hline No & 171 & 63 & 43 & 17 & 48 & \\
\hline Unkown & 322 & & & & & \\
\hline \multicolumn{7}{|l|}{$\begin{array}{l}\text { Residual } \\
\text { disease }\end{array}$} \\
\hline$\leq 1 \mathrm{~cm}$ & 817 & 281 & 215 & 64 & 257 & 0.932 \\
\hline$>1 \mathrm{~cm}$ & 124 & 41 & 35 & 11 & 37 & \\
\hline \multicolumn{7}{|l|}{ Histology } \\
\hline Serous & 795 & 275 & 206 & 65 & 249 & 0.725 \\
\hline Other & 146 & 47 & 44 & 10 & 45 & \\
\hline \multicolumn{7}{|l|}{ Grade } \\
\hline Well & 363 & 133 & 84 & 26 & 120 & 0.286 \\
\hline Moderate & 223 & 68 & 69 & 22 & 64 & \\
\hline Poorly & 253 & 89 & 63 & 18 & 83 & \\
\hline Unkown & 102 & & & & & \\
\hline \multicolumn{7}{|l|}{$\begin{array}{l}\text { Lymph node } \\
\text { stats }\end{array}$} \\
\hline Positive & 532 & 187 & 139 & 38 & 168 & 0.683 \\
\hline Negative & 409 & 135 & 111 & 37 & 126 & \\
\hline \multicolumn{7}{|l|}{ Rh factor } \\
\hline Positive & 937 & 319 & 250 & 74 & 294 & 0.125 \\
\hline Negative & 4 & 3 & 0 & 1 & 0 & \\
\hline \multicolumn{7}{|l|}{$\begin{array}{l}\text { CA125 at } \\
\text { diagnosis }\end{array}$} \\
\hline$\leq 35 \mathrm{U} / \mathrm{ml}$ & 55 & 19 & 12 & 5 & 19 & 0.851 \\
\hline$>35 \mathrm{U} / \mathrm{ml}$ & 886 & 303 & 238 & 70 & 275 & \\
\hline
\end{tabular}

FIGO, International Federation of Gynecology and Obstetrics.
Table 2. Relationship between B antigen and clinicopathological features in patients with ovarian cancer

\begin{tabular}{|c|c|c|c|}
\hline Characteristics & $\begin{array}{l}\text { Non-B antigen }(\mathrm{A} / \mathrm{O}) \\
(\mathrm{N}=616)\end{array}$ & $\begin{array}{l}\mathrm{B} \text { antigen }(\mathrm{B} / \mathrm{AB}) \\
(\mathrm{N}=325)\end{array}$ & $\begin{array}{l}P \\
\text { value }\end{array}$ \\
\hline $\begin{array}{l}\text { Age[median } \\
\text { (range),years] }\end{array}$ & $54(23-81)$ & $55(25-80)$ & \\
\hline$\leq 55$ & 331 & 172 & 0.813 \\
\hline$>55$ & 285 & 153 & \\
\hline \multicolumn{4}{|l|}{ Menopause } \\
\hline Yes & 353 & 189 & 0.802 \\
\hline No & 263 & 136 & \\
\hline \multicolumn{4}{|l|}{ FIGO stage } \\
\hline I & 29 & 22 & 0.092 \\
\hline II & 51 & 25 & \\
\hline III & 417 & 234 & \\
\hline IV & 119 & 44 & \\
\hline \multicolumn{4}{|c|}{$\begin{array}{l}\text { Family history of } \\
\text { cancer }\end{array}$} \\
\hline Yes & 202 & 105 & 0.880 \\
\hline No & 414 & 220 & \\
\hline \multicolumn{4}{|c|}{ Ascites at surgery } \\
\hline Yes & 309 & 139 & 0.333 \\
\hline No & 111 & 60 & \\
\hline \multicolumn{4}{|l|}{ Unkown } \\
\hline \multicolumn{4}{|c|}{ Residual disease } \\
\hline$\leq 1 \mathrm{~cm}$ & 538 & 279 & 0.520 \\
\hline$>1 \mathrm{~cm}$ & 78 & 46 & \\
\hline \multicolumn{4}{|l|}{ Histology } \\
\hline Serous & 524 & 271 & 0.498 \\
\hline Other & 92 & 54 & \\
\hline \multicolumn{4}{|l|}{ Grade } \\
\hline Well & 253 & 110 & 0.027 \\
\hline Moderate & 132 & 91 & \\
\hline Poorly & 172 & 81 & \\
\hline \multicolumn{4}{|l|}{ Unkown } \\
\hline \multicolumn{4}{|c|}{ Lymph node stats } \\
\hline Positive & 355 & 177 & 0.351 \\
\hline Negative & 261 & 148 & \\
\hline \multicolumn{4}{|l|}{ Rh factor } \\
\hline Positive & 613 & 324 & 0.688 \\
\hline Negative & 3 & 1 & \\
\hline \multicolumn{4}{|c|}{ CA125 at diagnosis } \\
\hline$\leq 35 \mathrm{U} / \mathrm{ml}$ & 38 & 17 & 0.560 \\
\hline$>35 \mathrm{U} / \mathrm{ml}$ & 578 & 308 & \\
\hline
\end{tabular}

\section{Subgroup analysis according to FIGO stage and menopause}

To evaluate the subgroups of ovarian cancer affected by presence of the $B$ antigen $(B / A B)$, we classified patients based on FIGO stage (I, n=51; II, $\mathrm{n}=76$; III, $\mathrm{n}=651 ; \mathrm{IV}, \mathrm{n}=163$ ) and menopause (Yes, $n=542 ;$ No, $n=399$ ). OS of FIGO stage I and IV were significantly worse for patients with presence of the $\mathrm{B}$ antigen $(\mathrm{B} / \mathrm{AB})(\mathrm{P}=0.009$ and $\mathrm{P}=0.035)$, but $\mathrm{OS}$ did not differ neither FIGO stage II nor III $(\mathrm{P}=0.279$ and $\mathrm{P}=0.219$ ) (Figure 3). OS of patients with menopause was notably worse for patients with presence of the $B$ antigen $(\mathrm{B} / \mathrm{AB})(\mathrm{P}=0.035)$, but $\mathrm{OS}$ of patients without menopause did not differ $(\mathrm{P}=0.119)$ (Figure 4).

\section{Discussions}

In this large, retrospective study, blood groups B and $A B$ were significantly associated with worse 
survival of ovarian cancer. The magnitude of the relationship was similar for blood group $B$ and $A B$ indicating that the $B$ antigen may affect ovarian progression. In analyses of presence of the $B$ antigen $(\mathrm{B} / \mathrm{AB})$ compared with absence of the $\mathrm{B}$ antigen $(\mathrm{A} / \mathrm{O})$, we observed a significantly worse survival in ovarian cancer with FIGO stage I, IV, and menopause.

Previous studies have suggested that the ABO blood group play an important role in the development of various cancers. As $\mathrm{ABO}$ antigens are expressed on the surface of several human tissues and cells, such as the ovary surface epithelial cells and ovarian inclusion cysts [17-18]. The relationship between the $\mathrm{ABO}$ blood group and the cancer risk has been intensely investigated across many different types of cancer, including pancreatic carcinoma, nasopharyngeal cancer, gastric carcinoma, lung carcinoma [19-22]. Besides, in a large, prospective study of women, individuals with presence of the $B$ antigen $(B / A B)$ were associated with increased risk of ovarian cancer [11]. However, previous retrospective studies have suggested that blood type A had an increased incidence of ovarian cancer [12-14]. Proposed reasons for these inconsistent findings were that participants in all studies were from different races, most retrospective reports did not adjust for other possible confounders, and several studies used hospital-based control individual, which may not represent the $\mathrm{ABO}$ distribution in the general population [12-13].
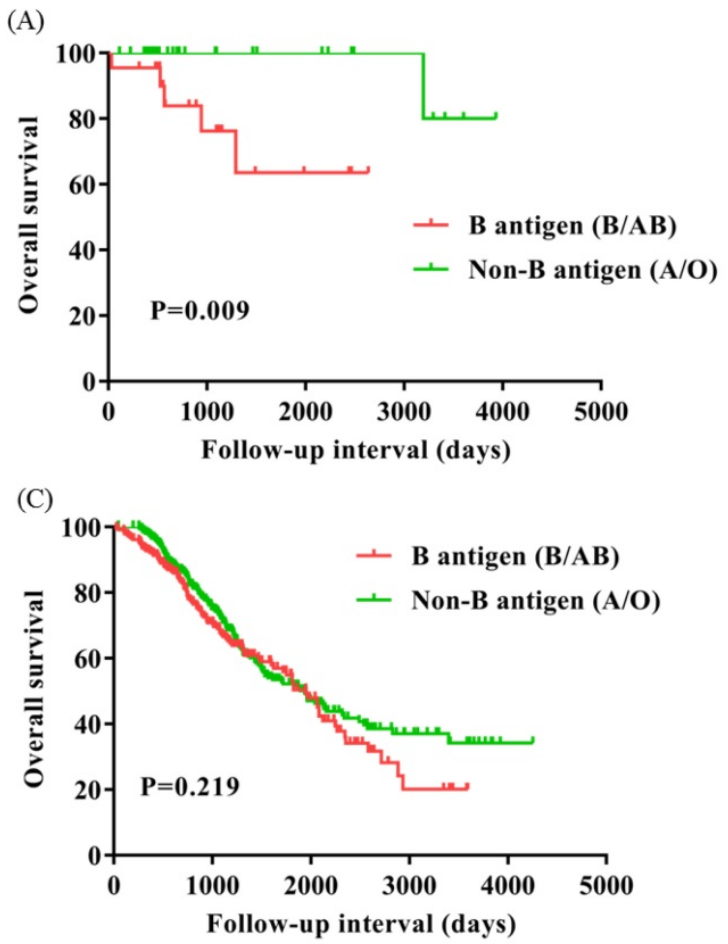

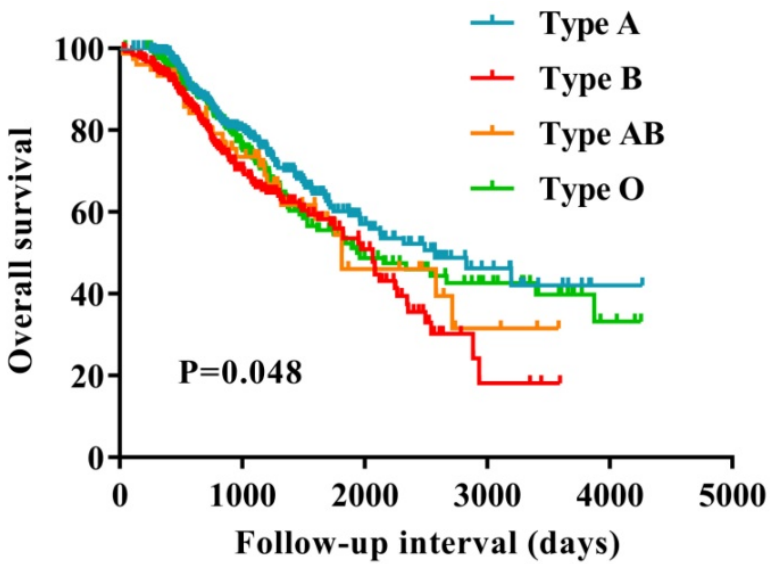

Figure 1. Overall survival for patients with ovarian cancer based on $A B O$ blood type. The patients in blood type $B$ showed significantly worse survival compared to the patients in the non-B blood types $(P=0.048)$.

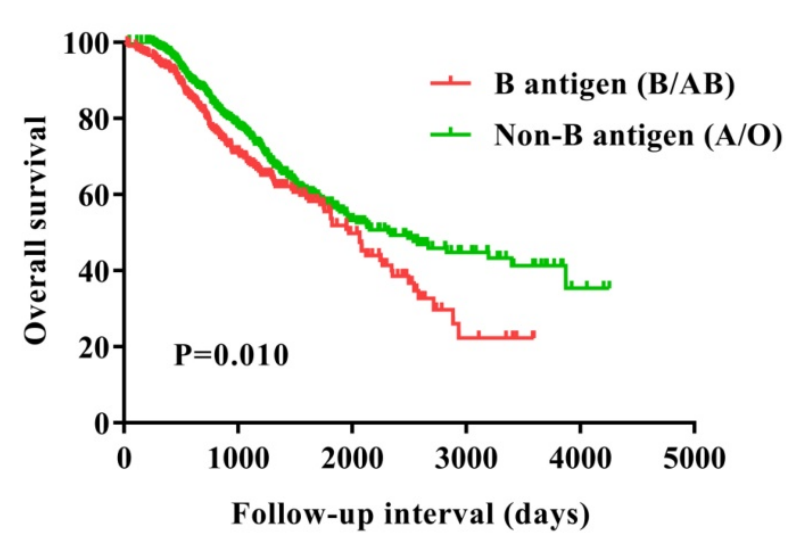

Figure 2. Overall survival for patients with ovarian cancer with $B$ antigen $(B / A B)$ and Non-B antigen $(A / O)$.
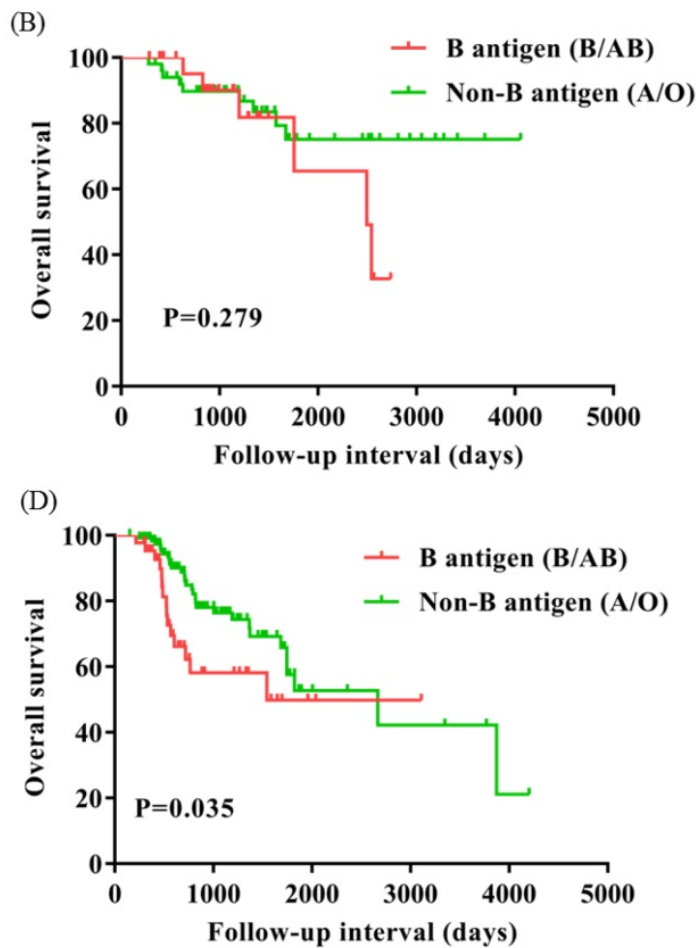

Figure 3. Overall survival for patients with ovarian cancer with $B$ antigen (B/AB) and Non-B antigen (A/O) in patients with FIGO stage I (A), II (B), III (C), and IV (D). 
(A)

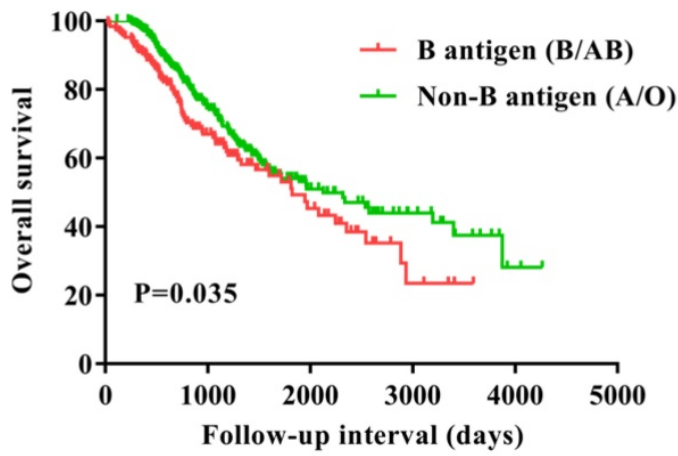

(B)

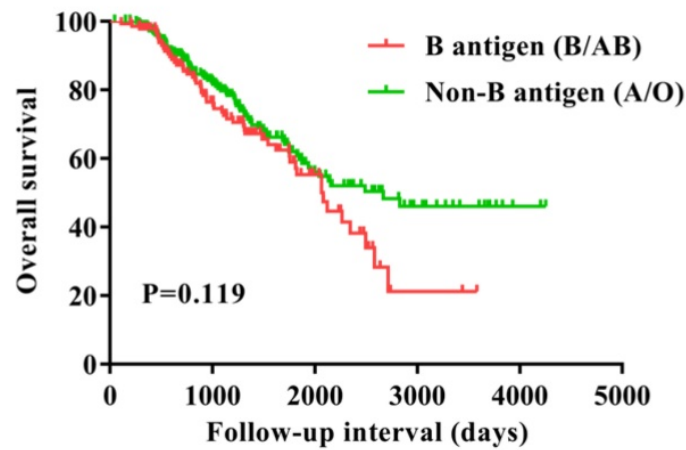

Figure 4.Overall survival for patients with ovarian cancer with $B$ antigen $(B / A B)$ and Non-B antigen $(A / O)$ in patients with menopause $(A)$ and Non-menopause (B).

Table 3. Overall survival analyses according to $A B O$ blood group in patients with ovarian cancer

\begin{tabular}{|c|c|c|c|c|c|c|}
\hline \multirow[t]{2}{*}{ Variables } & \multicolumn{3}{|c|}{ Univariate } & \multicolumn{3}{|c|}{ Multivariate } \\
\hline & HR & $95 \% \mathrm{CI}$ & $P$ value & HR & $95 \% \mathrm{CI}$ & $P$ value \\
\hline Age ( >55 vs. $\leq 55$ ) & 1.200 & $0.960-1.499$ & 0.109 & & & \\
\hline Menopause (No vs. Yes) & 1.288 & $1.027-1.615$ & 0.028 & 1.530 & $1.105-2.119$ & 0.010 \\
\hline \multicolumn{7}{|l|}{ FIGO stage } \\
\hline I & 0.317 & $0.135-0.744$ & 0.008 & 0.297 & $0.121-0.727$ & 0.008 \\
\hline II & 0.430 & $0.239-0.775$ & 0.005 & 0.476 & $0.247-0.919$ & 0.027 \\
\hline III & 1.099 & $0.796-1.516$ & 0.567 & 1.121 & $0.778-1.615$ & 0.541 \\
\hline IV & 1.000 & & & & & \\
\hline Family history of cancer (No vs. Yes) & 0.845 & $0.663-1.077$ & 0.173 & & & \\
\hline Ascites at surgery (No vs. Yes) & 1.706 & $1.166-2.497$ & 0.006 & 1.461 & $0.981-2.175$ & 0.062 \\
\hline Residual disease ( $>1 \mathrm{~cm}$ vs. $\leq 1 \mathrm{~cm}$ ) & 1.454 & $1.102-1.918$ & 0.008 & 1.163 & $0.735-1.841$ & 0.519 \\
\hline Histology (Other vs. Serous) & 1.113 & $0.826-1.500$ & 0.481 & & & \\
\hline \multicolumn{7}{|l|}{ Grade } \\
\hline Well & 0.830 & $0.583-1.182$ & 0.302 & & & \\
\hline Moderate & 1.119 & $0.862-1.453$ & 0.400 & & & \\
\hline Poorly & 1.000 & & & & & \\
\hline Lymph node stats (Negative vs. Positive) & 1.303 & $1.038-1.635$ & 0.022 & 0.924 & $0.656-1.301$ & 0.652 \\
\hline CA125 at diagnosis (>35 U/ml vs. $\leq 35 \mathrm{U} / \mathrm{ml}$ ) & 1.144 & $0.669-1.955$ & 0.624 & & & \\
\hline \multicolumn{7}{|l|}{ Blood type } \\
\hline A & 0.844 & $0.633-1.126$ & 0.249 & & & \\
\hline B & 1.258 & $0.947-1.671$ & 0.112 & & & \\
\hline $\mathrm{AB}$ & 1.147 & $0.752-1.749$ & 0.524 & & & \\
\hline $\mathrm{O}$ & 1.000 & & & & & \\
\hline$A$ antigen [Absent $(\mathrm{O} / \mathrm{B})$ vs.Present $(\mathrm{A} / \mathrm{AB})]$ & 0.807 & $0.642-1.015$ & 0.067 & & & \\
\hline$B$ antigen [Absent (O/A) vs. Present (B/AB)] & 1.342 & $1.069-1.685$ & 0.011 & 1.532 & 1.111-2.112 & 0.009 \\
\hline
\end{tabular}

There are also many studies have suggested a possible association between the $\mathrm{ABO}$ blood group and the clinical outcome in patients with malignant cancers. In 900 patients who underwent resection for renal cell carcinoma, the authors revealed that the non-O blood type was significantly associated with decreased OS [23]. Previous study about 404 patients undergoing resection for esophageal carcinoma, there was no relationship between the $\mathrm{ABO}$ blood type and the prognosis of esophageal cancer [24]. One study showed that blood group $\mathrm{A}$ and $\mathrm{AB}$ had a shorter $\mathrm{OS}$ than others in 333 patients undergoing resection for non-small cell lung cancer [25]. Meanwhile, two retrospective reports with a relatively small number of individuals enrolled, regarding the association between the $\mathrm{ABO}$ blood group and the clinical outcome of patients with ovarian cancer. Their findings suggested that a negative relationship between blood type A and ovarian cancer survival, but no relationship with blood type B [15-16]. Owing to these results, we hypothesized that whether blood type A or blood type B might associate with prognosis of ovarian cancer. We found that blood group B and $A B$ indicated worse survival in patients with ovarian cancer, especially in patients with FIGO I, IV, and menopause. The reasons for these conflicting results were that a relatively large number of participants enrolled without exclusion of FIGO stage IV, the proportions of ABO blood group were different. 256 patients with ovarian cancer in previous study, 60 patients had blood group A (23.4\%), 52 patients had blood group B (20.3\%), 24 patients had blood group 
$\mathrm{AB}(9.4 \%)$, and 120 patients had blood type O (46.9\%) [15]. 941 patients enrolled in our study, the $A B O$ distribution was 322 patients with blood type A $(34.2 \%), 250$ patients with blood type B (26.6\%), 75 patients with blood type $\mathrm{AB}(8.0 \%)$, and 294 patients with blood type $\mathrm{O}(31.2 \%)$.

The mechanisms of the $\mathrm{ABO}$ blood group and the survival of cancer have not been intensely investigated. As A and B antigens are also expressed on the ovarian cancer tissues [17-18]. We hypothesized that the $\mathrm{ABO}$ antigens in cancer cells contribute to the pathway signaling, intracellular adhesion, and inflammation, all of which play an important part in the progression of carcinoma [26]. The expression of $\mathrm{ABO}$ blood antigens on tumor cells was influenced by hyper-methylation of $\mathrm{ABO}$ promoter, which was associated with the tumor progression. $\mathrm{ABO}$ promoter hyper-methylation was also checked in dysplastic and hyperplastic tissues adjacent to tumor, indicating that it was an early event in the development of carcinoma [27]. Therefore, B antigen was correlated with the survival of patients in the FIGO stage I. The ABO gene, which is located on chromosome 9q34, encodes glycosyltransferases to form the $\mathrm{ABO}$ blood group antigens [28]. The $\mathrm{ABO}$ gene is one frequent region of deletion in ovarian cancer [29]. Aberrant glycosylation was one of the most important hallmarks of tumor [30]. Therefore, we speculate that patients with presence of $B$ antigen (B/AB) have more malignant cancer cells. Patients in the FIGO stage IV showed the worse survival.

There are several limitations of this analysis: first, this study was a retrospective and single-center analysis. Second, the clinical results regarding the $\mathrm{ABO}$ blood types were determined by a serological technique according to the phenotype, not the genotype. Third, all the participants of this analysis were Chinese, perhaps restricting the generalizability of these findings. Therefore, further investigations are required to clarify the reproducibility of this study, including the multi-center analysis and the investigation of different races from other countries.

In summary, our results show that there are a possible association between the B blood group antigen and worse clinical outcome of ovarian cancer. Patients with presence of the $B$ antigen (B/AB) had a significantly worse survival than those with non-B antigen (A/O), especially in patients with FIGO stage $\mathrm{I}$, IV, and menopause. However, given the inconsistent findings of previous studies, additional investigations are urgently needed to evaluate this association. Researches of potential mechanisms for a relationship between the $\mathrm{ABO}$ blood group and ovarian cancer prognosis also are needed.

\section{Acknowledgements}

We thank the enrolled patients and all the investigators, including the clinicians and laboratory technicians in this study. This analysis was supported by National Natural Science Foundation of China (contract/grant number: 81602615), General research program of Health Department of Zhejiang Province (contract/grant number: 2016KYB048) and Zhejiang Youth Talents Project (contract/grant number: 2019RC026).

\section{Competing Interests}

The authors have declared that no competing interest exists.

\section{References}

1. Reid BM, Permuth JB, Sellers TA. Epidemiology of ovarian cancer: a review. Cancer biology \& medicine. 2017; 14: 9-32.

2. Siegel RL, Miller KD, Jemal A. Cancer Statistics, 2017. CA: a cancer journal for clinicians. 2017; 67: 7-30.

3. Ozols RF, Bookman MA, Connolly DC, Daly MB, Godwin AK, Schilder RJ, et al. Focus on epithelial ovarian cancer. Cancer cell. 2004; 5: 19-24.

4. Nam EJ, Yoon H, Kim SW, Kim H, Kim YT, Kim JH, et al. MicroRNA expression profiles in serous ovarian carcinoma. Clinical cancer research : an official journal of the American Association for Cancer Research. 2008; 14: 2690-5.

5. Agarwal R, Kaye SB. Prognostic factors in ovarian cancer: how close are we to a complete picture? Annals of oncology : official journal of the European Society for Medical Oncology. 2005; 16: 4-6.

6. Clark TG, Stewart ME, Altman DG, Gabra H, Smyth JF. A prognostic model for ovarian cancer. British journal of cancer. 2001; 85: 944-52.

7. Holschneider $\mathrm{CH}$, Berek JS. Ovarian cancer: epidemiology, biology, and prognostic factors. Seminars in surgical oncology. 2000; 19: 3-10.

8. Khalili H, Wolpin BM, Huang ES, Giovannucci EL, Kraft P, Fuchs CS, et al. $\mathrm{ABO}$ blood group and risk of colorectal cancer. Cancer epidemiology, biomarkers \& prevention : a publication of the American Association for Cancer Research, cosponsored by the American Society of Preventive Oncology. 2011; 20: 1017-20.

9. Joh HK, Cho E, Choueiri TK. ABO blood group and risk of renal cell cancer. Cancer epidemiology. 2012; 36: 528-32.

10. Risch HA, Lu L, Wang J, Zhang W, Ni Q, Gao YT, et al. ABO blood group and risk of pancreatic cancer: a study in Shanghai and meta-analysis. American journal of epidemiology. 2013; 177: 1326-37.

11. Gates MA, Wolpin BM, Cramer DW, Hankinson SE, Tworoger SS. ABO blood group and incidence of epithelial ovarian cancer. International journal of cancer. 2011; 128: 482-6.

12. Osborne RH, Degeorge FV. The Abo Blood Groups in Neoplastic Disease of the Ovary. American journal of human genetics. 1963; 15: 380-8.

13. Henderson J, Seagroatt V, Goldacre M. Ovarian cancer and ABO blood groups. Journal of epidemiology and community health. 1993; 47: 287-9.

14. Mori M, Kiyosawa H, Miyake H. Case-control study of ovarian cancer in Japan. Cancer. 1984; 53: 2746-52.

15. Zhou J, Yang LC, He ZY, Li FY, Wu SG, Sun JY. Prognostic Impact of ABO Blood Group on the Survival in Patients with Ovarian Cancer. Journal of Cancer. 2015; 6: 970-5.

16. Marinaccio M, Traversa A, Carioggia E, Valentino L, Coviello M, Salamanna S, et al. [Blood groups of the $\mathrm{ABO}$ system and survival rate in gynecologic tumors]. Minerva ginecologica. 1995; 47: 69-76.

17. Le Pendu J, Marionneau S, Cailleau-Thomas A, Rocher J, Le Moullac-Vaidye B, Clement M. ABH and Lewis histo-blood group antigens in cancer. APMIS : acta pathologica, microbiologica, et immunologica Scandinavica. 2001; 109: 9-31.

18. Welshinger M, Finstad CL, Venkatraman E, Federici MG, Rubin SC, Lewis JL, Jr., et al. Expression of $\mathrm{A}, \mathrm{B}$, and $\mathrm{H}$ blood group antigens in epithelial ovarian cancer: relationship to tumor grade and patient survival. Gynecologic oncology. 1996; 62: 106-12.

19. Wang DS, Chen DL, Ren C, Wang ZQ, Qiu MZ, Luo HY, et al. ABO blood group, hepatitis $B$ viral infection and risk of pancreatic cancer. International journal of cancer. 2012; 131: 461-8.

20. Sheng L, Sun X, Zhang L, Su D. ABO blood group and nasopharyngeal carcinoma risk in a population of Southeast China. International journal of cancer. 2013; 133: 893-7.

21. Nakao M, Matsuo K, Ito H, Shitara K, Hosono S, Watanabe M, et al. ABO genotype and the risk of gastric cancer, atrophic gastritis, and Helicobacter pylori infection. Cancer epidemiology, biomarkers \& prevention : a 
publication of the American Association for Cancer Research, cosponsored by the American Society of Preventive Oncology. 2011; 20: 1665-72.

22. Urun Y, Utkan G, Cangir AK, Oksuzoglu OB, Ozdemir N, Oztuna DG, et al. Association of $\mathrm{ABO}$ blood group and risk of lung cancer in a multicenter study in Turkey. Asian Pacific journal of cancer prevention : APJCP. 2013; 14: 2801-3.

23. Kaffenberger SD, Morgan TM, Stratton KL, Boachie AM, Barocas DA, Chang $\mathrm{SS}$, et al. ABO blood group is a predictor of survival in patients undergoing surgery for renal cell carcinoma. BJU international. 2012; 110: E641-6.

24. Wang W, Liu L, Wang Z, Wei M, He Q, Ling T, et al. Impact of ABO blood group on the prognosis of patients undergoing surgery for esophageal cancer. BMC surgery. 2015; 15: 106

25. Fukumoto K, Taniguchi T, Usami N, Kawaguchi K, Fukui T, Ishiguro F, et al. The $\mathrm{ABO}$ blood group is an independent prognostic factor in patients with resected non-small cell lung cancer. Journal of epidemiology. 2015; 25: 110-6.

26. Hakomori S. Antigen structure and genetic basis of histo-blood groups A, B and O: their changes associated with human cancer. Biochimica et biophysica acta. 1999; 1473: 247-66.

27. Gao S, Worm J, Guldberg P, Eiberg H, Krogdahl A, Liu CJ, et al. Genetic and epigenetic alterations of the blood group $\mathrm{ABO}$ gene in oral squamous cell carcinoma. International journal of cancer. 2004; 109: 230-7.

28. Devlin J, Elder PA, Gabra H, Steel CM, Knowles MA. High frequency of chromosome 9 deletion in ovarian cancer: evidence for three tumour-suppressor loci. British journal of cancer. 1996; 73: 420-3.

29. Yazer $\mathrm{MH}$. What a difference 2 nucleotides make: a short review of $\mathrm{ABO}$ genetics. Transfusion medicine reviews. 2005; 19: 200-9.

30. Hakomori S. Glycosylation defining cancer malignancy: new wine in an old bottle. Proceedings of the National Academy of Sciences of the United States of America. 2002; 99: 10231-3. 